УДК 574.633

\title{
ОЦЕНКА КАЧЕСТВА ВОДЫ В СООБЩЕСТВАХ ДОННЫХ РАСТЕНИЙ ОЗЕРА КЕНОН ПО ПОКАЗАТЕЛЯМ ЗООБЕНТОСА
}

Шойдоков А. Б., студент, направление подготовки 05.03.06 Экология и природопользование, Забайкальский государственный университет, Чита

e-mail: shoidokov.a1998@gmail.com

Матафонов П. В., кандидат биологических наук, научный сотрудник лаборатории водных экосистем, Институт природных ресурсов, экологии и криологии СО РАН, Чита

e-mail: benthos@yandex.ru

\begin{abstract}
Аннотация. Озеро Кенон - мелководное озеро, имеющее важнейшее значение в теплоэнергетике и рекреации Забайкальского края. В рамках осуществляемого на озере государственного экологического мониторинга повышенное внимание уделяется влиянию хозяйственной деятельности на качество воды. В то же время качество воды в озере Кенон формируется и под влиянием природных факторов, определяемых особенностями функиионирования мелководных озер. До настоящего времени не было специильных исследований зообентоса зарослей макрофитов озера Кенон по показателям зообентоса. Целью исследования стала оценка качества воды в донных растительных сообществах с использованием зообентоса. Донные растения в исследовании были представлены преимущественно харовыми водорослями. В составе зообентоса обнаружено 18 таксонов. На мониторинговой станции «ТЭЦ» видовое разнообразие зообентоса в зарослях растительности составило 3,24 бит/экз., что соответствует чистым водам. Среднее значение биотического индекса Вудивиса на мониторинговых станциях в зарослях растительности составило 4,6 балла, что соответствует слабой степени загрязненности воды. Полученные результаты показывают второй - третий класс качества воды в зарослях макрофитов и сравнительно высокое качество воды в зарослях макрофитов вблизи ТЭЦ-1.
\end{abstract}

Ключевые слова: мелководные озера, озеро Кенон, качество воды, зообентос, харовые водоросли.

Для цитирования: Шойдоков А. Б., Матафонов П. В. Оценка качества воды в сообществах донных растений озера Кенон по показателям зообентоса // Шаг в науку. - 2020. - № 1. - С. 109-113.

\section{ASSESSMENT OF WATER QUALITY IN BOTTOM PLANTS OF LAKE KENON BY ZOOBENTHOS INDICATORS}

Shoydokov A. B., student, training direction 05.03.06 Ecology and environmental, Transbaikal State University, Chita

e-mail: shoidokov.a1998@gmail.com

Matafonov P. V., Candidate of Biological Sciences, researcher of laboratory of water ecosystems, Institute of Natural Resources, Ecology and Cryology of the Siberian Branch of the RAS, Chita e-mail: benthos@yandex.ru

Abstract. Lake Kenon is the shallow lake, which is importance in the heat power engineering and recreation of Transbaikal region. As part of the state environmental monitoring conducted on the lake, special attention is paid to the impact of economic activities on water quality. The state environmental monitoring pays key attention to the impact of economic activities on water quality. At the same time, the quality of lake Kenon water is formed under the influence of natural factors, determined by the shallow lakes functioning peculiarities. Up to date, there have been no special studies of the lake Kenon macrophyte thickets zoobenthos. The study aim was to estimate the water quality in bottom plants communities using zoobenthos. Bottom plants in the lake were presented mainly by charophyta algae. 18 taxons have been found in zoobenthos. At the «thermal power station» monitoring station the zoobenthos species diversity in the charophyta algae was 3,24 bit/ind., which corresponds to clean waters. The average value of the Woodiwiss biotic index in water plants on the monitoring stations was 4.6 points, which corresponds to a weak degree of water pollution. The study results indicate the second-third class of water quality in macrophyte thickets and relatively high water quality in macrophyte thickets near thermal power station.

Keywords: shallow lakes, water quality, zoobenthos, charophyta, lake Kenon.

Cite as: Shoidokov, A. B., Matafonov, P. V. (2020) [Assessment of water quality in the communities of bottom plants of Lake Kenon by zoobenthos indicators]. Shag v nauku [Step into science]. Vol. 1, pp. 109-113. 
Озеро Кенон - это важный объект промышленного (энергетического), рекреационного и эстетического значения для административного центра Забайкальского края - города Читы. Из-за своего расположения в центре города и высокой степени застройки прилегающей территории водоем подвергается достаточно большой рекреационной нагрузке, из-за воздействия на него объектов промышленности, железнодорожных и автомобильных магистралей, рекреационных зон и т.д., которые располагаются в пределах водосборной площади. Объектом, оказывающим наибольшее влияние на озеро, является Читинская ТЭЦ-1 [3].

Рекреационное и теплоэнергетическое назначения озера подразумевают довольно высокие требования к качеству воды и необходимость его мониторинга. Наиболее подробные исследования зообентоса выполнены в 1985-1991 годы [3]. В настоящее время на озере осуществляется оценка качества воды в рамках государственного экологического мониторинга, выполняемого в связи с функционированием ТЭЦ-1 [2]. Согласно теории функционирования мелководных озер [6] прозрачность и качество воды в озерах в значительной степени определяются составом и обилием донных макрофитов. В гидробиологических исследованиях на озере Кенон до настоящего времени не уделялось специального внимания оценке качества воды в донных растительных сообществах по показателям зообентоса.

Целью исследования стала оценка качества воды в растительных сообществах озера Кенон по показателям зообентоса.

Озеро Кенон расположено в бессточной котловине, в которую впадают Застепенский ручей, ручей Ивановский и река Кадалинка. Площадь поверхности озера составляет 16,2 км², максимальная длина озера 4,2 км, максимальная глубина пять метров [3]. По преобладающей в озере растительности озеро Кенон в 2011 г. можно было отнести к мелководным харовым озерам [1].

Отбор проб зообентоса выполнен 17 сентября 2010 г. и 10 августа 2011 г. на мониторинговых станциях исследования (рисунок 1, таблица 1). Растительность в пробах была представлена преимущественно харовыми водорослями.

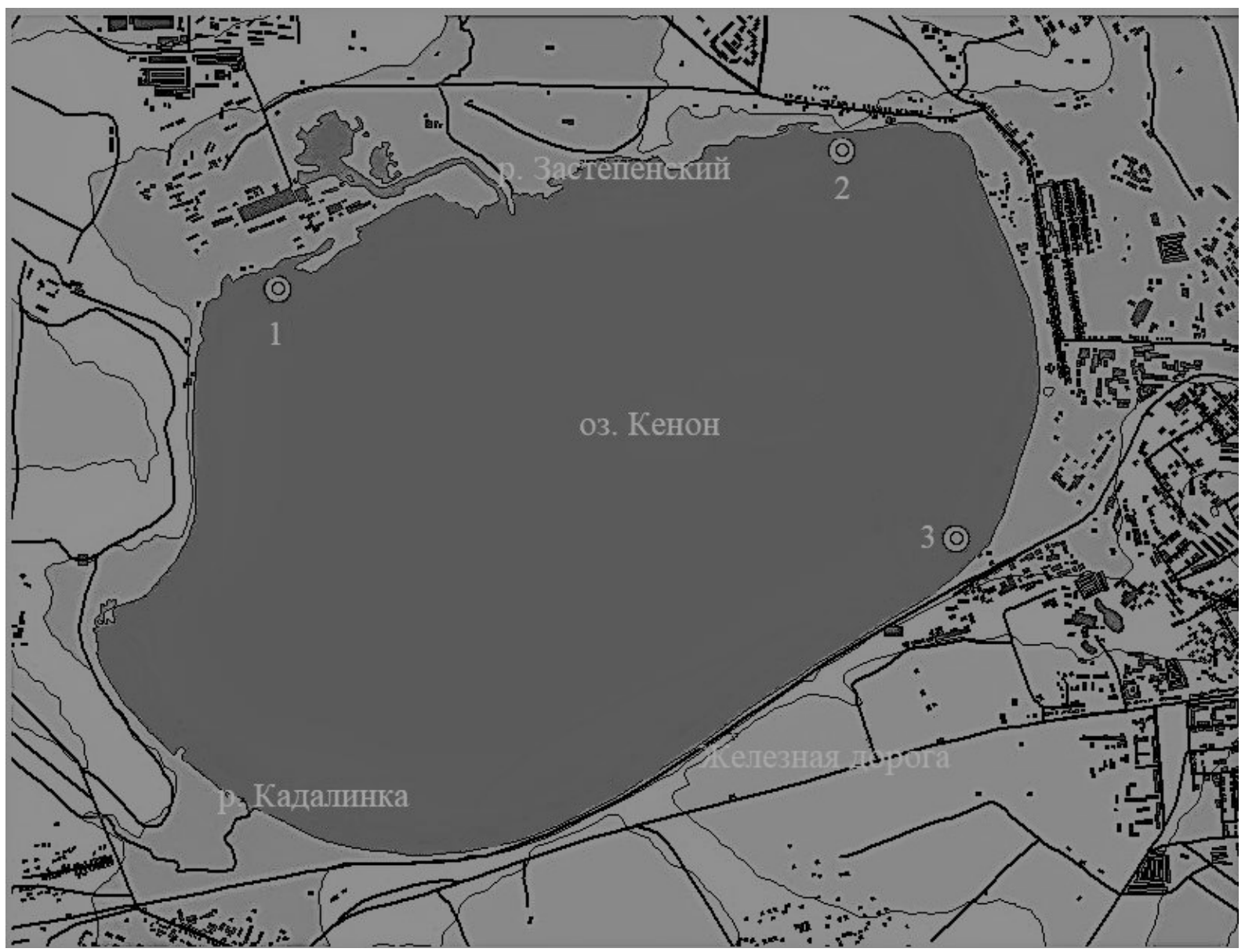

Рисунок 1. Схема станций отбора проб на озере Кенон. Мониторинговые станции: 1 - ТЭЦ, 2 - КСК, 3 - Нефтебаза 


\section{БИОЛОГИЧЕСКИЕ НАУКИ}

Таблица 1. Характеристика мониторинговых станций

\begin{tabular}{|l|c|c|c|c|c|c|}
\hline \multicolumn{1}{|c|}{ Год } & 2010 & \multicolumn{5}{|c|}{2011} \\
\hline Станция & ТЭЦ & \multicolumn{2}{|c|}{ ТЭЦ } & \multicolumn{2}{c|}{ КСК } & Нефтебаза \\
\hline Глубина, м & 1,2 & 0,7 & 1,2 & 1,0 & 1,0 & 3,7 \\
\hline Растения & $\begin{array}{c}\text { Харовые } \\
\text { водоросли }\end{array}$ & $\begin{array}{c}\text { Харовые } \\
\text { водоросли }\end{array}$ & $\begin{array}{c}\text { Харовые } \\
\text { водоросли }\end{array}$ & Рдест гребенчатый & $\begin{array}{c}\text { Харовые } \\
\text { водоросли }\end{array}$ & $\begin{array}{c}\text { Харовые } \\
\text { водоросли }\end{array}$ \\
\hline
\end{tabular}

Пробы зообентоса брали с использованием дночерпателя Петерсена (площадь захвата 0,025 $\mathrm{M}^{2}$ ). Отобранную пробу отмывали от мелких частиц грунта через мельничное сито с размером ячеек 0,3 мм и консервировали 4\% раствором формальдегида. Из отмытых от формалина проб выбраны организмы макрозообентоса с размерами тела 2-3 мм.

Оценка качества воды озера Кенон на всех станциях выполнена с использованием индекса Вудивиса ${ }^{1}$. Для определения класса качества воды, степени загрязненности воды и типа водоема использованы общепринятые классификации ${ }^{2}$. Для сопоставления с результатами предыдущих исследований по станции «ТЭЦ» дополнительно выполнена оценка качества воды с использованием рассчитанного по биомассе индекса Шеннона [5].

Зообентос зарослей растительности озера Кенон представлен 10 таксонамическими группами олигохетами, пиявками, гастроподами, бивалвиями, амфиподами, стрекозами, поденками, жуками, мокрецами и хирономидами (таблица 1,2 ). На станции «ТЭЦ» в районе сброса теплых вод в зообентосе харовых водорослей видовое обилие достигало 17 таксонов в пробе зообентоса (таблица 2), что оказывается выше, чем в зарослях растильности озера Арахлей, неподверженному значительному техногенному воздействию [4].

В зообентосе преобладали личинки хирономид Chironomus gr. annularis и поденки Caenis sp., coставив 58\% численности и 45,6\% биомассы.

Таблица 2. Численность (N) и биомасса (B) зообентоса на станции ТЭЦ в зарослях харовых водорослей в 2011 г.

\begin{tabular}{|c|c|c|}
\hline Таксон & $\mathrm{N}$, эКз./M² & $\mathrm{B}, \Gamma / \mathrm{M}^{2}$ \\
\hline \multicolumn{3}{|l|}{ Oligochaeta } \\
\hline Chaetogaster limnaei Baer, 1827 & 40 & 0,08 \\
\hline \multicolumn{3}{|l|}{ Hirudinea } \\
\hline Glossiphonia heteroclite (Linne) & 40 & 0,04 \\
\hline \multicolumn{3}{|l|}{ Gastropoda } \\
\hline Lymnaea sp. & 160 & 2,44 \\
\hline \multicolumn{3}{|l|}{ Amphipoda } \\
\hline Gmelinoides fasciatus (Stebbing, 1899) & 200 & 0,60 \\
\hline Gammarus lacustis Sars, 1863 & 160 & 0,80 \\
\hline \multicolumn{3}{|l|}{ Coleoptera } \\
\hline Haliplus confinis Stephens, 1829 & 360 & 0,96 \\
\hline \multicolumn{3}{|l|}{ Odonata } \\
\hline Enallaghma cyathigerum Charpentier, 1840 & 600 & 2,84 \\
\hline \multicolumn{3}{|l|}{ Ephemeroptera } \\
\hline Caenis horaria (L., 1958) & 4080 & 4,04 \\
\hline \multicolumn{3}{|l|}{ Diptera } \\
\hline Ceratopogonidae & & \\
\hline
\end{tabular}

\footnotetext{
1 Руководство по методам гидробиологического анализа поверхностных вод и донных отложений / [Ред. В. А. Абакумов] Ленинград: Изд-во Гидрометеоиздат, 1983. - 173 с.

2 РД 52.24.309-2016 «Организация и проведение режимных наблюдений за состоянием и загрязнением поверхностных вод суши» [Электронный ресурс]. - Информационно-правовой портал Гарант.py. - 2019. - Режим доступа: http://base.garant.ru/70467386/. (дата обращения: 27 ноября 2019 г.).
} 


\begin{tabular}{|c|c|c|}
\hline Таксон & $\mathrm{N}$, эКз./. $\mathrm{M}^{2}$ & $\mathrm{~B}, \Gamma / \mathrm{M}^{2}$ \\
\hline Sphaeromias pictus (Meigen 1818) & 120 & 0,40 \\
\hline \multicolumn{3}{|l|}{ Chironomidae } \\
\hline Psectorcladius gr. sordidellus & 160 & 0,16 \\
\hline Cricotopus gr. cylindraceus & 600 & 0,20 \\
\hline Ablabesmyia gr. monilis & 1320 & 1,60 \\
\hline Paratanytarsus quintuplex Kieffer, 1922 & 3680 & 1,04 \\
\hline Chironomini gen sp. & 440 & 0,08 \\
\hline Chironomus gr. annularis & 7800 & 5,56 \\
\hline Glyptotendipes sp. & 520 & 0,20 \\
\hline Parahironomus kuzini Shilova, 1969 & 40 & 0,04 \\
\hline Всего & 20320 & 21,00 \\
\hline
\end{tabular}

Видовое разнообразие зообентоса здесь составило 3,24 бит/экз., что согласуется с результатами предыдущих исследований, согласно которым индекс разнообразия в этой части озера находился на уровне 3,0 бит/экз. [3]. Полученное значение разнообразия зообентоса свидетельствует о чистых водах.
Число таксонов зообентоса на обследованных станциях в зарослях растительности изменялось от четырех до семи (таблица 3). Наибольшее таксономическое разнообразие зообентоса отмечено на станции «ТЭЦ».

Таблица 3. Таксономический состав зообентоса на мониторинговых станциях

\begin{tabular}{|c|c|c|c|c|}
\hline \multirow{2}{*}{ Группы организмов } & \multicolumn{4}{|c|}{ Мониторинговые станции } \\
\hline & ТЭЦ 2010 & ТЭЦ 2011 & КСК & Нефтебаза \\
\hline Тип Annelida Класс Oligochaeta & + & + & - & - \\
\hline \multicolumn{5}{|l|}{ Тип Mollusca } \\
\hline Класс Gastropoda & + & + & + & + \\
\hline Класс Bivalvia & - & - & - & + \\
\hline \multicolumn{5}{|l|}{ Тип Arthropoda } \\
\hline Класс Amphipoda & + & + & + & + \\
\hline \multicolumn{5}{|l|}{ Класс Insecta } \\
\hline Отряд Coleoptera & + & + & + & - \\
\hline Отряд Trichoptera & - & + & - & - \\
\hline Отряд Odonata & + & + & - & - \\
\hline \multicolumn{5}{|l|}{ Отряд Diptera } \\
\hline \multicolumn{5}{|l|}{ Ceratopogonidae } \\
\hline Семейство Chironomidae & + & + & + & + \\
\hline Число таксонов & 6 & 7 & 4 & 4 \\
\hline
\end{tabular}

Показатели качества воды, выполненные с использованием индекса Вудивиса представлены в таблице 4.

Таблица 4. Оценка качества воды на мониторинговых станциях

\begin{tabular}{|c|c|c|c|c|}
\hline \multirow{2}{*}{ Показатели } & \multicolumn{4}{|c|}{ Мониторинговые станции } \\
\hline & ТЭЦ, 2010 г. & ТЭЦ, 2011 г. & КСК & Нефтебаза \\
\hline $\begin{array}{l}\text { Биотический индекс Вудивиса, } \\
\text { балл }\end{array}$ & 5 & 6 & 4 & 4 \\
\hline Степень загрязненности воды & Слабо загрязненная & Слабо загрязненная & Загрязненная & Загрязненная \\
\hline Класс качества воды & II & II & III & III \\
\hline Тип водоема & $\begin{array}{c}\text { Альфа- } \\
\text { мезосапробный }\end{array}$ & $\begin{array}{c}\text { Бета- } \\
\text { мезосапробный }\end{array}$ & $\begin{array}{c}\text { Альфа- } \\
\text { мезосапробный }\end{array}$ & $\begin{array}{c}\text { Альфа- } \\
\text { мезосапробный }\end{array}$ \\
\hline
\end{tabular}


По данным государственного экологического мониторинга [2] придонные воды и грунты озера Кенон характеризуются средним биотическим индексом 3-4 балла. Среднее значение биотического индекса Вудивиса в зарослях растительности в озере Кенон в 2010-2011 годы по нашим данным оказалось чуть выше и составило 4,6 балла, что соответствует второму классу качества и слабой степени загрязненности воды.

Полученные результаты впервые дают представление о зообентосе зарослей донных макрофитов озера Кенон и качестве воды в этих зарослях, оцененном по показателям зообентоса. Результаты исследования зообентоса выявили второй - третий класс качества воды в зарослях растительности озера Кенон. Сравнительно высокое разнообразие зоо- бентоса и качество воды в районе ТЭЦ-1 согласуется с результатами предыдущих исследований, выявивших высокое разнообразие зообентоса в этой части озера [3]. В дальнейших исследованиях рекомендуется уделять внимание влиянию зарослей растительности на формирование качества воды в озере Кенон.

Благодарности. Авторы выражают благодарность кандидату биологических наук, Л. Н. Золотаревой за оказание консультативной помощи.

Работа выполнена в рамках Проекта IX.137.1.3. «Биоразнообразие природных и природно-техногенных экосистем Забайкалья (Центральной Азии), как индикатор динамики региональных изменений климата», № госрегистрации AAAAA17-117011210078-9.

\section{Литература}

1. Базарова Б. Б. Многолетние изменения растительности озера Кенон (Забайкальский край) // Известия Иркутского гос. ун-та. Серия «Биология. Экология». - 2012. - Т. 5. - № 4. - С. 18-23.

2. Буйволов Ю. А., Гончарова М. В., Лазарева Г. А., Корнилова М. Б., Быкова И. В., Юренков К. В., Юренков М. В., Уваров А.Г. - Ежегодник состояния экосистем поверхностных вод России (по гидробиологическим показателям) 2011 год - М.: Росгидромет, 2013. - 145 с.

3. Итигилова М. Ц., Чечель А.П., Замана Л.В. Экология городского водоема : монография. - Новосибирск: Издательство СО РАН, 1998. - 260 с.

4. Матафонов П. В. Пространственное распределение литорального зообентоса в озере Арахлей в маловодный период // Международный журнал прикладных и фундаментальных исследований. - № 5. 2018. - С. 180-184.

5. Финогенова Н. П., Алимов А. Ф. Оценка степени загрязнения вод по составу донных животных // Методы биологического анализа пресных вод - Л: Издательство ЗИН АН СССР, 1976. - С. 95-106.

6. Scheffer M., Egbert H. Shallow lakes theory revisited: various alternative regimes driven by climate, nutrients, depth and lake size // Hydrobiologia. - 2007. - Vol. 584. - P. 455-466.

Статья поступила в печать: 20.01.2020; принята в печать: 11.03.2020. 